Nadja Dobnik

UDK [81'25:33]:378(497.4)

Ekonomska fakulteta, Univerza v Ljubljani

DOI: $10.4312 /$ vestnik.11.7-28

Slovenija

nadja.dobnik@ef.uni-lj.si

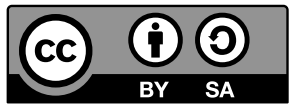

\title{
NEKATERE TEŽAVE MLADIH PREVAJALCEV PRI PREVAJANJU STROKOVNIH BESEDIL - PRIMERI NAPAK V PREVODIH KOMERCIALNEGA BESEDILA
}

UVOD

V izobraževanju bodočih strokovnih in tehničnih prevajalcev imajo besedila s področja ekonomije in poslovnega sveta pomembno mesto. Skupaj z besedili z drugih strokovnih področij, kot so pravo, turizem, medicina in številna druga, predstavljajo izhodišče za razvijanje znanj, spretnosti in kompetenc, s pomočjo katerih se bodo študenti v bodočem poklicu prevajalca spopadali s strokovnimi in tehniškimi besedili različnih vrst. Študenti prevajalstva na Oddelku za prevajalstvo Filozofske fakultete Univerze v Ljubljani (FFUL) se začnejo s prevajanjem strokovnih besedil srečevati pri predmetih prevajanja v slovenščino, kjer se poleg splošnih, publicističnih, poljudno znanstvenih in literarnih besedil srečajo tudi s besedili s področja poslovnih ved, ekonomije, prava, turizma, EU, tehničnih ved. Ta besedila pogosto pomenijo prvi korak v jezik stroke, obenem pa tudi prvi korak k spoznavanju vloge prevajalca kot posrednika med dvema stranema s konkretnimi in včasih zelo različnimi pričakovanji in zahtevami (prodajalec-kupec, naročnik-izvajalec ipd.). Za razliko od številnih študijskih programov prevajalstva, ki potekajo predvsem na podiplomski ravni in kjer imajo študenti praviloma že nekaj delovnih izkušenj in predhodno pridobljeno visoko izobrazbo, so študenti prevajalstva na FFUL mladi dodiplomski študenti, ki se v študij vpišejo takoj po srednji šoli, imajo izrazito literarno-humanistično izobrazbo in zelo malo izkušenj. Za njih prevajanje strokovnih besedil pomeni obenem jezikovno-prevajalsko izkušnjo in spoznavanje sveta, v katerem strokovna besedila nastajajo. To predstavlja specifičen didaktičen izziv, saj mora poučevanje neizogibno zajemati tako predmetno-specifične vsebine - razvijanje jezikovnih in prevajalskih kompetenc - kot tudi vsebine in strategije, ki mladega prevajalca ozaveščajo o številnih zunajbesedilnih dejavnikih, pomembnih za besedilo in njegovo prevajanje.

Analiza napak v prevodih dodiplomskih študentov prevajalstva je del obsežne empirične raziskave, namenjene zbiranju podatkov o različnih vrstah težav in napak v prevodih študentov in ovrednotenju teh napak z vidika dejanskih in pričakovanih prevajalskih 
kompetenc študentov. Pri spremljanju prvih generacij študentov prevajanja (od 1999/2000 do 2010/2011) in analizi njihovih prevodov se je namreč izkazalo, da se poleg napak, za katere smo predvidevali, da jih bodo študenti naredili in so bile del didaktičnih ciljev predmeta, redno pojavljajo tudi napake, ki jih po naših predvidevanjih študenti ne bi smeli narediti. Namen raziskave je bil preučiti, kakšne nepričakovane napake se pojavljajo sistematično, kateri so vzroki za te napake in kaj nam povedo o pričakovanih in dejanskih kompetencah študentov. Rezultati prve raziskave so bili objavljeni leta 2011 (Dobnik, 2011), raziskava je zajela analizo prevodov 6 avtentičnih besedil, ki jih je prevajalo 8 generacij študentov med letoma 1999 in 2011. Rezultati te raziskave so pomembno vplivali na nadaljnje delo s študenti, model raziskave pa ostaja podlaga za analizo napak in spremljanje študentov. Pričujoča raziskava zajema del rezultatov prve raziskave (obdobje 1999/2000 do 2010/2011) ter 3 generacije po tem obdobju (2011/2012, 2012/2013 in 2014/2015), saj smo presodili, da je z vidika celovitejšega vpogleda $\mathrm{v}$ težave študentov daljše časovno obdobje pomembno.

Sistematično spremljanje težav in napak v prevodih študentov je sestavni del razvijanja prevajalskih kompetenc (Nord, 1992; Gile, 2005; Pokorn, 2019). V prvi vrsti predstavlja informacijo za študenta, ki lahko na podlagi lastnih napak in težav ozavesti postopke in principe prevajalske dejavnosti ter ovrednoti svoje znanje in kompetence. Prav tako je pomembna tudi za učitelja, ki lahko na podlagi ugotovljenih napak preverja raven prevajalske zmožnosti študentov, načrtuje ustrezne aktivnosti v skupini, predvidi najprimernejša besedila za prevajanje, obenem pa mu pomaga ovrednotiti napredovanje študentov in načrtovati mentorsko delo.

\section{2}

\section{VZROKI NAPAK V PREVODIH}

Preučevanje napak in vzrokov za težave pri prevajanju je kompleksno in razvejano področje raziskovanja, $\mathrm{s}$ temi vprašanji so se ukvarjali domala vsi teoretiki in zlasti praktiki prevajanja (Newmark, 1988; Nord, 1992; Pym, 1992; Déjean Le Féal, 1993; Kussmaul, 1995; Dancette, 1997; Kiraly, 2000; Bastin, 2003; Gile, 2005; Kockaert, 2014; Eyckmans, 2017; Pokorn, 2019, in številni drugi). Paul Kussmaul v svojem delu Training the Translator (1995) kot vzroke za neuspešne miselne procese pri prevajanju posebej izpostavlja: interferenco (interferences); strah pred interferenco (fear of interferences); napačno prisojanje enega samega pomena (faulty one-to-one correspondences); neustrezno uporabo dvojezičnih slovarjev (misuse of bilingual dictionaries); napačno uporabo splošnega znanja in lastnih izkušenj (misuse of world knowledge and one's own experiences) ter nepopolno izpeljava parafraziranja (incomplete paraphrasing).

Medtem ko se Kussmaul ukvarja $\mathrm{z}$ napakami in miselnimi procesi pri prevajanja v najširšem smislu, pa smo pri analizi napak v prevodih študentov dodatno izhajali iz ugotovitev Daniela Gila, ki v knjigi La traduction. La comprendre, l'apprendre (2005) 
na podlagi lastnega pedagoškega dela in raziskav analizira težave in napake mladih prevajalcev. Razdeli jih na pomenske napake (fautes de sens), na jezikovne napake in težave (fautes et maladresses de langue) in na težave pri strokovni terminologiji in frazeologiji (faiblesses dans la terminologie et la phraséologie spécialisées).

Pomenske napake pripisuje predvsem naslednjim vzrokom: nezadostnemu znanju izhodiščnega jezika; premalo pozornemu branju izhodiščnega besedila; slabi kakovosti izhodiščnega besedila; površnemu izražanju oz. tvorjenju ciljnega besedila; »mehanskim« napakam pri pisanju (ciljnega besedila).

Jezikovne napake in težave pripisuje predvsem nezadostnemu obvladovanju ciljnega jezika; (trenutnemu) vplivu izhodiščnega jezika na ciljni jezik; globlji nesposobnost prevajalca, da bi se pri preoblikovanju v ciljni jezik odtrgal od jezikovnih struktur izhodiščnega besedila; površnemu preformuliranju ter odsotnosti preverjanja sprejemljivosti izrekov, izraženih v ciljnem jeziku.

Težave pri prevajanju strokovne terminologije in frazeologije pa izhajajo iz tega, da študent bodisi sploh ni raziskoval, da se je nepravilno odločal med viri ali da je vire neustrezno uporabil.

Gile (2005) kot dva ključna vidika težav študentov navaja nezadostna znanja, tako jezikovna kot zunajjezikovna, ter težave, povezane s pogoji za delo, pri čemer gre lahko na primer za premajhno motivacijo študenta, da bi prevod dobro izpeljal do konca, za slabe pogoje za delo (prekratki roki za oddajo, nedostopnost virov) in podobno.

Dodiplomski študenti Oddelka za prevajalstvo FFUL se v 2. in 3. letniku pri predmetu Prevajanje iz francoščine $v$ slovenščine srečajo $z$ več besedili s področja ekonomije in komercialnega poslovanja, med drugim z dvema primeroma prodajnih pogojev (Splošni prodajni pogoji za nakup vina, Prodajni pogoji za nakup vina »en primeur«). V 2. letniku je prevajanje prodajnih pogojev za študente prvi stik s prevajanjem besedila komercialne narave. Študenti se v svojem življenju kot potrošniki sicer dnevno srečujejo s postopkom nakupa, vsak nakup pomeni odnos, urejen z določenimi pravnimi določili (pravicami in obveznostmi), vendar ta določila ozavestimo šele ali izključno v primeru težav ali sporov. Prav tako o zakonitostih te vrste odnosov ne razmišljamo skozi jezikovne ali skladenjske razsežnosti, pri branju prodajnih pogojev smo praviloma površni ali jih preskočimo. »Prodajni pogoji« za študente kot potrošnike torej niso neznano in težko predstavljivo področje, saj v to vrsto odnosov vstopajo vsakodnevno, zato smo pri izbiri dokumenta „Conditions générales de vente« presodili, da gre za didaktično vsestransko zanimivo besedilo: študenti se srečajo z avtentičnim dokumentom, spoznajo strokovno besedišče pravno-komercialne narave, za ustrezen prevod morajo dobro razumeti odnose med udeleženci v postopku in poiskati ustrezne vire in izraze v slovenščini. 
Namen analize napak v prevodih tega besedila je zbrati podatke o vrstah napak in težav posamezne generacije, primerjati rezultate z ugotovitvami o napakah in težavah predhodnih generacij ter na podlagi te primerjave presoditi o izboru vaj in besedil za nadaljnje delo v skupini, bodisi v istem semestru ali v naslednjem.

Besedilo »Conditions générales de vente« je strokovno besedilo komercialne narave, objavljeno kot del zgibanke, ki jo je vinogradnoško posestvo Ruhlmann pripravilo za obiskovalce posestva in kleti. Zgibanka zajema ponudbo vin letnika 1994-1995 s cenikom (carte des vins), naročilnico (bulletin de commande), opisom značilnosti alzaških vin (caractéristiques des vins d'Alsace) in splošnimi prodajnimi pogoji (conditions de vente). Namen avtorja besedila je seznaniti potencialne kupce vin s pogoji prodaje (cene, pogoji plačila in dostave, način naročanja, ugodnosti). Posestvo Ruhlmann obstaja še danes in ima svojo ponudbo vin objavljeno na spletni strani.

Za strukturo besedila je značilna členitev po pravno-komercialnih določilih, ki so ključnega pomena za sklenitev posla (naročila), ter razdelitev po alineah. Gre za strokoven jezik s področja komercialnega poslovanja s pravno-komercialni strokovnimi izrazi in formulacijami. V primerjavi s podobnimi dokumenti to besedilo sicer ni strukturirano po členih (1. člen, 2. člen itd.), v nekaterih odstavkih je jezik tudi manj formalen (uporaba 1. in 2. osebe množine), kar kaže na to, da je avtor po vsej verjetnosti prilagodil besedilo potrebam situacije. Stil je jedrnat, formalen, z značilno uporabo trpnika, kratkimi jedrnatimi stavki, nominalnimi strukturami in pridevniškimi polstavki. Na ravni besedišča gre za vrsto specifičnih komercialnih in pravno-komercialnih strokovnih izrazov v povezavi s potekom in zakonitostmi komercialnega poslovanja (razumevanje poteka sklenitve naročila in poznavanje zakonitosti komercialnega poslovanja za ustrezno prevajanje določenih izrazov).

V analizo je vključenih 160 prevodov 11 generacij študentov 2. letnika od študijskega leta 1999/2000 do 2014/2015. Študenti so besedilo dobili v študijskem gradivu na začetku semestra, prevajali so ga doma in ga morali oddati do določenega datuma in ure (kar je bil pogoj za pristop h kolokviju ali izpitu).

Omeniti je treba, da je generacija 2003/2004 besedilo prevajala pod enakimi pogoji (doma), vendar za oceno, kar v nekaterih primerih pojasni večjo motivacijo pri formuliranju končnih rešitev in sodelovanje med študenti pri nekaterih zahtevnih izrazih. 


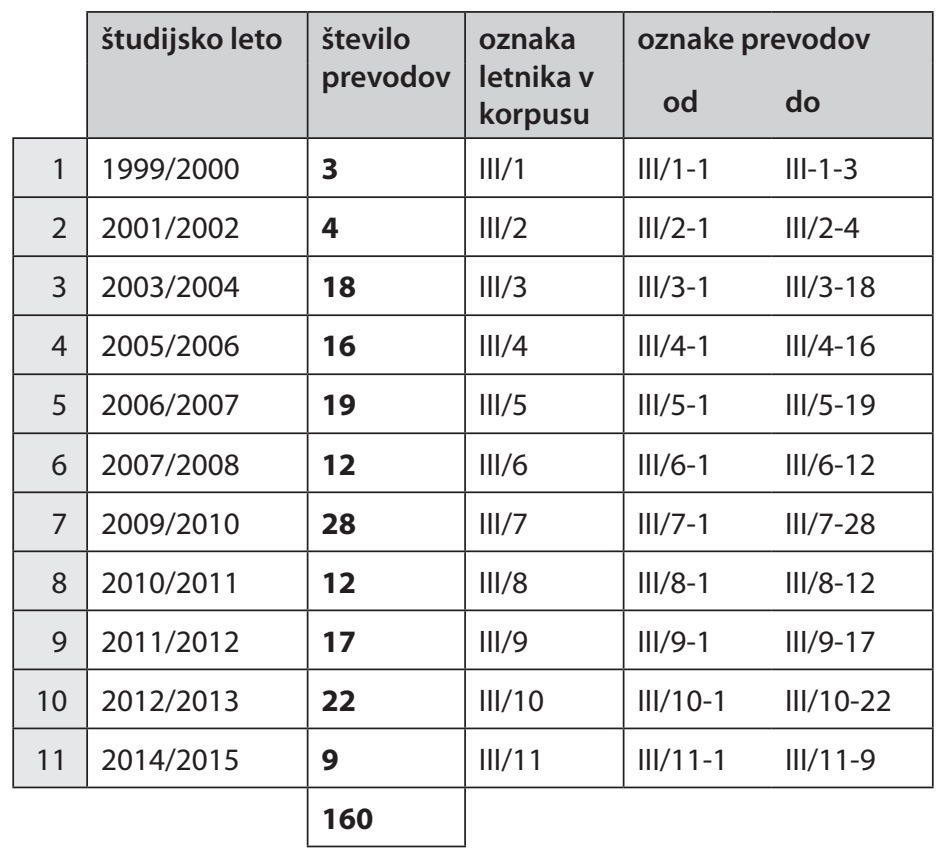

V raziskavo smo vključili izbrane komercialne izraze in nekatere povedi s poudarjeno pravno-komercialno skladnjo:

1. Nos prix s'entendent départ cave.

2. Droits, TVA, verre et emballage compris.

3. Frais de port à votre charge.

4. Bon de transport SNCF à tarif réduit

5. Livreur

6. Agréées au départ de nos caves, les marchandises voyagent sous la responsabilité des transporteurs et destinataires.

7. Dans l'intérêt de nos clients, nous leur conseillons de vérifier nos colis en présence du livreur et de faire immédiatement les réserves qui s'imposent en cas d'avarie ou de litige.

8. Nous pouvons y joindre votre carte. 


\section{REZULTATI EMPIRIČNE RAZISKAVE}

\section{Primer 1:}

Nos prix s'entendent départ cave.

\begin{tabular}{|l|l|l|}
\hline študijsko leto / skupina & $\begin{array}{l}\text { število } \\
\text { prevodov }\end{array}$ & $\begin{array}{l}\text { pomensko ustrezni ali } \\
\text { sprejemljivi prevodi }\end{array}$ \\
\hline $1999 / 2000-$ III/1 & 3 & 0 \\
\hline $2001 / 2002-$ III/2 & 4 & 1 \\
\hline $2003 / 2004-$ III/3 & 18 & 13 \\
\hline $2005 / 2006-$ III/4 & 16 & 0 \\
\hline $2006 / 2007-$ III/5 & 19 & 0 \\
\hline $2007 / 2008-$ III/6 & 12 & 1 \\
\hline $2009 / 2010-$ III/7 & 28 & 2 \\
\hline $2010 / 2011-$ III/8 & 12 & 0 \\
\hline $2011 / 2012-$ III/9 & 17 & 3 \\
\hline $2012 / 2013-$ III/10 & $\mathbf{2 2}$ & 15 \\
\hline $2014 / 2015-$ III/11 & $\mathbf{9}$ & 7 \\
\hline skupaj & 160 & 32 \\
\hline
\end{tabular}

Primeri pomensko ustreznih ali sprejemljivih prevodov:

Navedene cene veljajo franko vinska klet. (III/2-2)

Cene franko klet. (III/3-2)

Naše cene veljajo franko skladišče. (III/7-12)

Naše cene so Ex Works. (III/11-6)

Primeri neustreznih prevodov:

Cene so odvisne od zaloge vina. (III/3-5)

Naše cene se ujemajo s cenami vinskih kleti. (III/4-1)

Cene vin določa ponudnik. (III/7-6)

Naše cene so »départ cave«. (III/10-16)

Naše cene so iz kleti. (III/10-7)

Analiza napak pokaže, da je imela velika večina - kar $80 \%$ - težave z ustreznim prevodom te povedi. Gre za določilo oz. strokovno formulacijo, ki se uporablja v komercialnem poslovanju in pomeni točko/mesto, do katere je prodajalec odgovoren za izdelek, ki ga prodaja; nadaljnja odgovornost in stroški (prevoza, zavarovanja ipd.) s tem preidejo na kupca. Gre za primer strokovnega frazema, ki študenta na samem začetku prisili k iskanju pomena in ustrezne prevodne rešitve. S splošnim, tudi dobrim znanjem francoščine 
namreč ni mogoče razumeti te povedi, prav tako je treba v slovenščini poiskati izraz, ki ga za to vrsto situacije uporabljajo komercialisti.

Primeri neustreznih prevodov kažejo na to, da se študenti, ki so sicer vedeli, da gre za komercialno besedilo, niso dovolj potrudili, da bi razčistili pomen te povedi v kontekstu komercialnega poslovanja. Izraz so prevajali dobesedno, intuitivno ali po lastnih predstavah, kar je pripeljalo do nekaterih povsem napačnih in nesmiselnih prevodnih rešitev.

Didaktično je zelo zanimiva ugotovitev, da so nekateri študenti pri iskanju ustreznega prevoda vprašali za nasvet starše (ekonomiste, komercialiste) in so jim ti pravilno svetovali (»Cene so franko tovarna«), vendar se je študentom zdela ta rešitev preveč nenavadna in se pri končni redakciji prevoda zanjo niso odločili.

Primeri ustreznih prevodov pa v nekaterih primerih razkrijejo situacijo, ki je obratna od nezaupanja v predlagano rešitev, namreč sodelovanje med študenti in »prepisovanje» prevodnih rešitev. Tak je primer generacije 2003-2004. Ko študenti prevajajo doma, te možnosti nikoli ni mogoče izključiti, pogovor s študenti pa razkrije, da zatekanje k prevzemanju prevodnih rešitev od kolegov pogosto ni znak premajhne zavzetosti ali lenobe. Zlasti v velikih skupinah je sodelovanje pogosto, študenti pa se posvetujejo predvsem pri resnih prevodnih zagatah. Prepisovanje brez razumevanja je vedno dvorezen meč, vendar $\mathrm{v}$ primeru zelo specifičnih strokovnih izrazov in frazemov (kot je navedeni) zelo pogosto pomeni ustrezno rešitev. Študenti praviloma od kolegov prepišejo le tiste prevodne rešitve, ki jih povsem nedvoumno prepoznajo kot problem in sami ne najdejo rešitve, druge, na videz razumljive in neproblematične, pa prevedejo sami in to pogosto neustrezno, kar razkrije nerazumevanje konteksta in neustrezno dokumentiranje. Omeniti pa je vseeno treba, da ima sodelovanje med študenti včasih za posledico kolektivno nesmiselne prevodne rešitve ali celotne prevode, kar pokaže na hujšo neresnost in nezainteresiranost študentov.

\section{Primer 2:}

Droits, TVA, verre et emballage compris.

\begin{tabular}{|l|l|l|}
\hline študijsko leto / skupina & $\begin{array}{l}\text { število } \\
\text { prevodov }\end{array}$ & $\begin{array}{l}\text { pomensko ustrezni ali } \\
\text { sprejemljivi prevodi }\end{array}$ \\
\hline $1999 / 2000-$ III/1 & 3 & 2 \\
\hline $2001 / 2002-$ III/2 & 4 & 2 \\
\hline $2003 / 2004-$ III/3 & 18 & 10 \\
\hline $2005 / 2006-$ III/4 & 16 & 13 \\
\hline $2006 / 2007-$ III/5 & 19 & 10 \\
\hline $2007 / 2008-$ III/6 & 12 & 6 \\
\hline
\end{tabular}




\begin{tabular}{|l|l|l|}
\hline študijsko leto / skupina & $\begin{array}{l}\text { število } \\
\text { prevodov }\end{array}$ & $\begin{array}{l}\text { pomensko ustrezni ali } \\
\text { sprejemljivi prevodi }\end{array}$ \\
\hline $2009 / 2010-$ III/7 & 28 & 20 \\
\hline $2010 / 2011-$ III/8 & 12 & 8 \\
\hline $2011 / 2012-$ III/9 & 17 & 10 \\
\hline $2012 / 2013-$ III/10 & 22 & 12 \\
\hline $2014 / 2015-$ III/11 & 9 & 4 \\
\hline skupaj & 160 & 97 \\
\hline
\end{tabular}

Primeri pomensko ustreznih ali sprejemljivih prevodov:

Vanje so vključeni davki, DDV, steklenice in embalaža. (III/1-1)

Dajatve, DDV, steklo in embalaža so všteti v ceno. (III/3-9)

Vključujejo pristojbine, davek, steklo in embalažo. (III/7-4)

Primeri neustreznih prevodov:

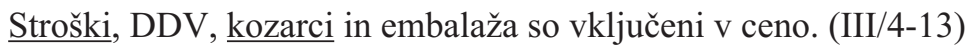

Pravice, TVA, kozarci in pakiranje všteto. (III/5-1)

Pri analizi napak sta nas prvi vrsti zanimala izraza »droits« in »verre«, ki ju študenti praviloma poznajo, vendar v drugačnem pomenu. Analiza napak je pokazala, da je $40 \%$ študentov ta dva izraza prevedlo neustrezno, kar kaže na površnost pri branju in razumevanju besedila v kontekstu komercialnega poslovanja ter neustrezno iskanje virov. Prevodi izrazov »droits« in »verre« kot »pravice« in »kozarci« kažejo predvsem na neustrezno uporabo dvojezičnega slovarja in/ali na prisojanje najbolj splošnega in prevajalcu znanega pomena, brez razmisleka o pomenu in smiselnosti v konkretni (komercialni) situaciji.

Za razliko od Primera 1, ki je bil študentom vsebinsko nerazumljiv, sta se izraza »droits« in »verre« za nekatere študente izkazala za zavajajoča prav zato, ker na prvi pogled nista bila nerazumljiva in jima zato niso pripisali ustreznega strokovnega (komercialnega) pomena.

\section{Primer 3:}

\section{Frais de port à votre charge}

\begin{tabular}{|l|l|l|}
\hline študijsko leto / skupina & $\begin{array}{l}\text { število } \\
\text { prevodov }\end{array}$ & $\begin{array}{l}\text { pomensko ustrezni ali } \\
\text { sprejemljivi prevodi }\end{array}$ \\
\hline $1999 / 2000-$ III/1 & 3 & 0 \\
\hline $2001 / 2002-$ III/2 & 4 & 2 \\
\hline $2003 / 2004-$ III/3 & 18 & 15 \\
\hline
\end{tabular}




\begin{tabular}{|l|l|l|}
\hline študijsko leto / skupina & $\begin{array}{l}\text { število } \\
\text { prevodov }\end{array}$ & $\begin{array}{l}\text { pomensko ustrezni ali } \\
\text { sprejemljivi prevodi }\end{array}$ \\
\hline $2005 / 2006-$ III/4 & 16 & 11 \\
\hline $2006 / 2007-$ III/5 & 19 & 6 \\
\hline $2007 / 2008-$ III/6 & 12 & 3 \\
\hline $2009 / 2010-$ III/7 & 28 & 19 \\
\hline $2010 / 2011-$ III/ 8 & 12 & 8 \\
\hline $2011 / 2012-$ III/9 & 17 & 10 \\
\hline $2012 / 2013-$ III/10 & 22 & 8 \\
\hline $2014 / 2015-$ III/11 & 9 & 5 \\
\hline skupaj & 160 & 87 \\
\hline
\end{tabular}

Primeri pomensko ustreznih ali sprejemljivih prevodov:

dostava; stroški dostave; stroški prevoza; transportni stroški; prevozni stroški; stroški pošiljanja; stroški prevoza

Dostavo plačate sami. (III/2-2)

Stroške prevoza krijete sami. (III/5-10)

Primeri neustreznih prevodov:

poštnina, stroški poštnine, stroški za poštnino; potni stroški; pristanišče, pristaniška pristojbina

Poštnino plačate sami. (III/10-1)

Potne stroške vam zaračunamo. (III/1-2)

Takojšni odvoz iz pristanišča na vaše stroške. (III/6-10)

Hitra dostava na dom po naročilu (III/4-1)

Analiza napak razkrije, da je imela približno polovica študentov težave pri izbiri ustreznega izraza. Pri neustreznih prevodnih rešitvah gre za več vrst težav:

- pri izrazu »poštnina« gre delno za površnost in neustrezno izbiro glede na situacijo, vendar pa tudi za prevzemanje iz slovenskih internetnih virov (spletne strani slovenskih podjetij), kjer se izraz "poštnina« dejansko pojavlja v pomenu »stroški prevoza«. To bi bil morda ustrezen izraz za manjše količine, pri večjih pošiljkah pa dostave ne bi izvajala pošta, zlasti ne v mednarodnem prometu;

- $\quad$ pri izrazu »potni stroški« gre za bodisi za nepoznavanje, predvsem pa za površnost, saj se izraz ne uporablja za stroške dostave oz. transporta blaga;

- pri izrazu »pristanišče« in »pristaniški« gre za nepremišljeno, avtomatsko pripisovanje najpogostejšega pomena ( ki pa v tej situaciji nima pomena (npr. III/4-1, III/5-4). 


\section{Primer 4:}

\section{Bon de transport SNCF à tarif réduit}

\begin{tabular}{|l|l|l|}
\hline študijsko leto / skupina & $\begin{array}{l}\text { število } \\
\text { prevodov }\end{array}$ & $\begin{array}{l}\text { pomensko ustrezni ali } \\
\text { sprejemljivi prevodi }\end{array}$ \\
\hline $1999 / 2000-$ III/1 & 3 & 1 \\
\hline $2001 / 2002-$ III/2 & 4 & 0 \\
\hline $2003 / 2004-$ III/3 & 18 & 3 \\
\hline $2005 / 2006-$ III/4 & 16 & 5 \\
\hline $2006 / 2007-$ III/5 & 19 & 6 \\
\hline $2007 / 2008-$ III/6 & 12 & 4 \\
\hline $2009 / 2010-$ III/7 & 28 & 9 \\
\hline $2010 / 2011-$ III/8 & 12 & 6 \\
\hline $2011 / 2012-$ III/9 & 17 & 5 \\
\hline $2012 / 2013-$ III/10 & 22 & 8 \\
\hline $2014 / 2015-$ III/11 & 9 & 4 \\
\hline skupaj & 160 & 51 \\
\hline
\end{tabular}

Primeri pomensko ustreznih ali sprejemljivih prevodov:

Sprejemamo bone za prevoz s SNCF po znižani ceni. (III/1-3)

Sprejemamo SNCF bone za transport po znižani ceni. (III/5-15)

Sprejemamo transportne vavčerje SNCF po znižani tarifi. (III/11-5)

Primeri neustreznih prevodov:

Sprejemamo kupone javnega prometa po znižani ceni. (III/1-1)

Sprejemamo zadolžnice za prevoz SNCF po znižani ceni. (III/5-6)

Sprejmemo subvencije za prevoz (SCNF - francoske železnice) po znižani tarifi. (III5-7)

Obveznice železniškega prevoza sprejmemo po znižani ceni. (III/6-12)

Sprejemamo bone za popust pri prevozu. (III/9-13)

Sprejmemo bone podjetja SNCB za prevoz po nižji tarifi. (III/7-4)

sprejemamo bone agencije SCFN za prevoz po znižani ceni. (III/7-8)

Analiza napak in težav pokaže, da je le $30 \%$ študentov ta izraz prevedla pomensko ustrezno.

Izraz »bon de transport SNCF « predstavlja obenem komercialni frazem in kulturno-specifični izraz. Kot komercialni frazem pomeni plačilno sredstvo, ki se uporablja v železniškem tovornem prometu, kot kulturno-specifični izraz pa plačilno sredstvo, ki se uporablja v Franciji, medtem ko pri nas tega plačilnega sredstva ne poznamo. Izraz 
"vavčer«, ki so ga izbrali 3 od vseh študentov, se zdi smiseln, saj vavčer pomeni »dokument o vnaprejšnjem plačilu določenih storitev«. V Sloveniji ta izraz poznamo v poslovanju turističnih agencij kot potovalni vavčer, v prevodu bi bila torej smiselna rešitev »transportni vavčer« ali »vavčer za transport«.

Študenti vseh generacij so imeli s prevodom tega izraza veliko težav, saj razumevanje zahteva določeno poznavanje komercialne prakse. Prevodna rešitev »transportni boni«, za katero se je odločila približno tretjina študentov, se zdi smiseln kompromisni kalk. Pogovor s študenti je razkril, da so se nekateri študenti za to rešitev sicer odločili po liniji najmanjšega odpora, veliko študentov pa zato, ker kljub iskanju niso našli ničesar primerljivega ali ustreznega v slovenskem železniškem prometu. Ta vrsta kompromisnega kalka se zdi dobra rešitev predvsem v primerjavi z nekaterimi primeri neustreznih prevodov, pri katerih so se študenti hoteli izogniti dobesednemu posnemanju.

Pri neustreznih prevodih se pojavi več vrst težav. Z didaktičnega vidika so najbolj zanimive prevodne rešitve, pri katerih so se študenti hoteli izogniti dobesednemu prevodu (uporabi izraza »boni«), vendar so izbrali izraz, ki ima zelo specifičen pomen in točno določen pomen na drugem področju, npr. »obveznice«, »subvencije«, »tovorni listi«. Ta vrsta napake - izogibanje dobesednemu prevodu z izbiro napačnega in zavajajočega izraza - je pri mladih prevajalcih pogosta, zato je pomembna za ozaveščanje študentov. Druga didaktično zanimiva, pogosta in nevarna napaka je kombinacija nepoznavanja zunajbesedilne reference $-\mathrm{v}$ tem primeru SNCF - in površnost pri zapisu (npr. SNCB, $\mathrm{SCFN}$ ), kar v prevodu pripelje do bralcu povsem neznanega in nerazumljivega pojma: »boni podjetja $\mathrm{SNCB} «$ ali »boni agencije $\mathrm{SCFN} «(\mathrm{III} / 7-8)$.

\section{Primer 5: \\ livreur}

Dans l'intérêt de nos clients, nous leur conseillons de vérifier nos colis en présence du livreur et de faire immédiatement les réserves qui s'imposent en cas d'avarie ou de litige.

\begin{tabular}{|l|l|l|}
\hline študijsko leto / skupina & $\begin{array}{l}\text { število } \\
\text { prevodov }\end{array}$ & $\begin{array}{l}\text { pomensko ustrezni ali } \\
\text { sprejemljivi prevodi }\end{array}$ \\
\hline $1999 / 2000-\mathrm{III} / 1$ & 3 & 1 \\
\hline $2001 / 2002-\mathrm{III} / 2$ & 4 & 2 \\
\hline $2003 / 2004-\mathrm{III} / 3$ & 18 & 12 \\
\hline $2005 / 2006-\mathrm{III} / 4$ & 16 & 10 \\
\hline $2006 / 2007-\mathrm{III} / 5$ & 19 & 10 \\
\hline $2007 / 2008-\mathrm{III} / 6$ & 12 & 5 \\
\hline $2009 / 2010-\mathrm{III} / 7$ & 28 & 22 \\
\hline
\end{tabular}




\begin{tabular}{|l|l|l|}
\hline študijsko leto / skupina & $\begin{array}{l}\text { število } \\
\text { prevodov }\end{array}$ & $\begin{array}{l}\text { pomensko ustrezni ali } \\
\text { sprejemljivi prevodi }\end{array}$ \\
\hline $2010 / 2011-$ III/8 & 12 & 8 \\
\hline $2011 / 2012-$ III/9 & 17 & 9 \\
\hline $2012 / 2013-$ III/10 & 22 & 8 \\
\hline $2014 / 2015-$ III/11 & 9 & 5 \\
\hline skupaj & 160 & 92 \\
\hline
\end{tabular}

Primeri pomensko ustreznih ali sprejemljivih prevodov:

ustrezno: dostavljavca; osebe, ki jim jo je dostavila; izvajalca transporta; prevoznika tudi: dostavljalca; dostavnika; dostavitelja; odgovornega za dostavo

Strankam svetujemo, da preverijo vsebino pošiljk v prisotnosti dostavljavca ... (III/8-1)

Primeri neustreznih prevodov:

napačno ali neustrezno: dobavitelja; pošiljatelja; kurirja, raznašalca

$\mathrm{V}$ interesu naših strank svetujemo, da preverijo vsebino paketov v prisotnosti dobavitelja ... (III/9-10)

Analiza pokaže, da je 40 \% študentov izraz »livreur« prevedla napačno. Neustrezne prevodne rešitve pokažejo na več vrst težav:

- prevod »dobavitelj« pomeni hudo pomensko napako, ne glede na to, ali je vzrok neustrezno razumevanje odnosov med subjekti komercialnega poslovanja, površnost pri branju in preoblikovanju ali avtomatska uporaba dvojezičnega slovarja;

- pestra izbira variacij izraza »dostavljavec« kaže v nekaterih primerih na napačno uporabo dvojezičnega slovarja (»dostavitelj«) ali uporabo izraza, ki se je študentu zdel domač (»dostavnik«, »dostavljalec«, »raznašalec«) brez preverjanja. Vendar pa $\mathrm{v}$ vseh teh primerih pomen ostaja jasen, gre predvsem za neustrezno preverjanje $\mathrm{v}$ slovenski terminologiji.

Primer 6:

Agréées au départ de nos caves, les marchandises voyagent sous la responsabilité des transporteurs et destinataires.

\begin{tabular}{|l|l|l|}
\hline študijsko leto / skupina & $\begin{array}{l}\text { število } \\
\text { prevodov }\end{array}$ & $\begin{array}{l}\text { pomensko ustrezni ali } \\
\text { sprejemljivi prevodi }\end{array}$ \\
\hline $1999 / 2000-$ III/1 & 3 & 2 \\
\hline $2001 / 2002-$ III/2 & 4 & 2 \\
\hline
\end{tabular}




\begin{tabular}{|l|l|l|}
\hline študijsko leto / skupina & $\begin{array}{l}\text { število } \\
\text { prevodov }\end{array}$ & $\begin{array}{l}\text { pomensko ustrezni ali } \\
\text { sprejemljivi prevodi }\end{array}$ \\
\hline $2003 / 2004-$ III/3 & 18 & 14 \\
\hline $2005 / 2006-$ III/4 & 16 & 8 \\
\hline $2006 / 2007-$ III/5 & 19 & 8 \\
\hline $2007 / 2008-$ III/6 & 12 & 5 \\
\hline $2009 / 2010-$ III/7 & 28 & 15 \\
\hline $2010 / 2011-$ III/8 & 12 & 6 \\
\hline $2011 / 2012-$ III/9 & 17 & 10 \\
\hline $2012 / 2013-$ III/10 & 22 & 12 \\
\hline $2014 / 2015-$ III/11 & 9 & 5 \\
\hline skupaj & 160 & 87 \\
\hline
\end{tabular}

Primera pomensko ustreznih prevodov:

Po odobreni odpremi iz naših kleti potuje blago na odgovornost prevoznikov in naslovnikov. (III/3-15)

Po odpravi blaga iz naših kleti je dostava pošiljk v celoti odgovornost prevoznika in naslovnika. (III/4-10)

Primeri neustreznih prevodov:

Za registrirano blago so solidni prevozniki in naslovniki takoj po tem, ko ga odpeljejo iz naših kleti. (III/1-2)

Odobrite prevoz naših zalog, trgovsko blago potuje na odgovornost prevoznikov in prejemnikov. (III/5-4)

$\mathrm{Z}$ našim dovoljenjem blago potuje na odgovornost prevoznikov in prejemnikov. (III/6-2)

Analiza prevodnih rešitev je pokazala, da je imela polovica vseh študentov težave s prevodom te povedi. Med pomensko ustrezne ali sprejemljive prevodne rešitve smo uvrstili vse prevode, iz katerih je razvidno, da so študenti razumeli pomen tega določila in so to izrazili na razumljiv način, čeprav ne vedno v primerno formalnem registru. Med sprejemljive smo uvrstili tudi prevode z izpustom dela povedi, če izpust ni prizadel pomena celotnega določila.

Glavna težava, ki smo jo pričakovali, je bilo razumevanje in ustrezno preoblikovanje pridevniškega polstavka na začetku povedi, ki je karakteristična za francosko skladnjo $v$ formalnem in novinarskem načinu pisanja. Iz primerov prevodov smo lahko sklepali, da so težave z razumevanjem povezane predvsem s premalo pozornim in natančnim branjem in premalo vztrajnosti pri preoblikovanju. Nazorno je dejstvo, da je generacija 2003/2004 to besedilo prevajala za oceno (domači kolokvij): študenti so se 
bolj potrudili in rezultati to potrjujejo: 14 prevodov od 18 je bilo pomensko ustreznih ali sprejemljivih.

Glede na to, da gre za pomemben del prodajnih pogojev, je odstotek neustreznih in napačnih prevodov pomembno opozorilo za študente.

\section{Primer 7:}

Dans l'intérêt de nos clients, nous leur conseillons de vérifier nos colis en présence du livreur et de faire immédiatement les réserves qui s'imposent en cas d'avarie ou de litige.

\begin{tabular}{|l|l|l|}
\hline študijsko leto / skupina & $\begin{array}{l}\text { število } \\
\text { prevodov }\end{array}$ & $\begin{array}{l}\text { pomensko ustrezni ali } \\
\text { sprejemljivi prevodi }\end{array}$ \\
\hline $1999 / 2000-$ III/1 & 3 & 0 \\
\hline $2001 / 2002-$ III/2 & 4 & 1 \\
\hline $2003 / 2004-$ III/3 & 18 & 10 \\
\hline $2005 / 2006-$ III/4 & 16 & 5 \\
\hline $2006 / 2007-$ III/5 & 19 & 7 \\
\hline $2007 / 2008-$ III/6 & 12 & 2 \\
\hline $2009 / 2010-$ III/7 & 28 & 20 \\
\hline $2010 / 2011-$ III/8 & 12 & 6 \\
\hline $2011 / 2012-$ III/9 & 17 & 7 \\
\hline $2012 / 2013-$ III/10 & 22 & 12 \\
\hline $2014 / 2015-$ III/11 & 9 & 4 \\
\hline skupaj & 160 & 74 \\
\hline
\end{tabular}

Primeri pomensko ustreznih ali sprejemljivih prevodov:

Strankam, v njihovo dobro, priporočamo, da preverijo naše pakete $\mathrm{v}$ prisotnosti dostavljalca in se v primeru nastale škode takoj pritožijo. (III/2-2)

Strankam svetujemo, da preverijo našo pošiljko v prisotnosti odgovornega za dostavo in $\mathrm{v}$ primeru morebitnih nepravilnosti ali poškodb nemudoma prijavijo reklamacijo. (III/4-10)

V dobro naših kupcev le-tem svetujemo, da pošiljke preverijo v prisotnosti dostavljavca in da v primeru poškodb ali drugih napak morebitne reklamacije podajo na licu mesta. (III/6-5)

Primeri neustreznih prevodov:

$\mathrm{V}$ dobro naših strank svetujemo, da v prisotnosti dobavitelja preverijo pakete in da v primeru nastale škode ob prevozu ali sporov takoj naročijo rezervno blago. (III/7-25) 
Prevoznikom, v interesu do naših kupcev, priporočamo, da v prisotnosti dobaviteljev pregledajo naše pakete ter da v primeru nastale škode ali spora takoj pripravijo novo zalogo (III/8-3)

Naročnikom svetujemo, da po prejemu pošiljke, v prisotnosti dobavitelja pakete pregledajo in le-te v primeru škode ali drugih nepravilnosti takoj nadomestijo. (III/8-5)

Zaradi interesa naših strank jim svetujemo, da pregledajo paket v prisotnosti dobavitelja ter naredijo rezervacije, ki se uveljavijo v primeru škode ali v primeru spora. (III/11-7)

Analiza napak pokaže, da je več kot polovica študentov to poved prevedla neustrezno ali celo povsem nesmiselno. Pričakovali smo, da bodo imeli študenti zaradi formalnega sloga in pravno-komercialnih formulacij pri preoblikovanju v slovenščino podobne težave kot pri Primeru 6. Celotna poved, predvsem njen drugi del, zahteva natančno branje, predvsem pa pozorno razčlenitev in natančno preoblikovanje. Čeprav gre za formalni slog, ta poved pomensko ne vsebuje kulturno specifičnih elementov ali pojmov, ki bi zahtevali posebno védenje, brez katerega študent - tudi potencialni kupec - ne bi mogel razumeti sporočila, vsekakor pa je treba v ustreznih virih preveriti pomen pravno-formalnih izrazov (npr. faire les réserves, en cas d'avarie, en cas de litige) in prevodne ustreznice.

Analiza prevodov pokaže, da so se študenti večinoma zadovoljili s hitrim in površnim branjem, ki ni pripeljalo do dovolj natančnega razumevanja, premalo truda pa so vložili tudi v redakcijo končne verzije prevoda. Iz nekaterih primerov (navedenih zgoraj) je tudi razvidno, da so študenti popolnoma zamešali vloge deležnikov v izpeljavi dostave in prevzema blaga. Del te povedi je tudi izraz »livreur« (Primer 5) - napačen prevod tega izraza dodatno vpliva na pomen in smiselnost te povedi.

Iz izkušenj in iz pogovora s študenti je mogoče zgolj kot pojasnilo (nikakor opravičilo) dodati, da je veliko število neustreznih in slabih prevodov te povedi povezano $\mathrm{z}$ dejstvom, da gre za predzadnjo poved $\mathrm{v}$ besedilu, ko je koncentracija in motivacija študentov pogosto bistveno manjša. Primeri neustreznih prevodov kažejo na to, da so se študenti premalo potrudili pri preoblikovanju, predvsem pa jih večina ni razmislila o ustreznosti besednih zvez in kolokacij v svojem prevodu ter o smiselnosti prevoda.

\section{Primer 8:}

Nous pouvons y joindre votre carte.

\begin{tabular}{|l|l|l|}
\hline študijsko leto / skupina & $\begin{array}{l}\text { število } \\
\text { prevodov }\end{array}$ & $\begin{array}{l}\text { pomensko ustrezni ali } \\
\text { sprejemljivi prevodi }\end{array}$ \\
\hline $1999 / 2000-$ III/1 & 3 & 0 \\
\hline $2001 / 2002-$ III/2 & 4 & 3 \\
\hline
\end{tabular}




\begin{tabular}{|l|l|l|}
\hline študijsko leto / skupina & $\begin{array}{l}\text { število } \\
\text { prevodov }\end{array}$ & $\begin{array}{l}\text { pomensko ustrezni ali } \\
\text { sprejemljivi prevodi }\end{array}$ \\
\hline $2003 / 2004-$ III/3 & 18 & 9 \\
\hline $2005 / 2006-$ III/4 & 16 & 3 \\
\hline $2006 / 2007-$ III/5 & 19 & 5 \\
\hline $2007 / 2008-$ III/6 & 12 & 5 \\
\hline $2009 / 2010-$ III/7 & 28 & 12 \\
\hline $2010 / 2011-$ III/8 & 12 & 6 \\
\hline $2011 / 2012-$ III/9 & 17 & 5 \\
\hline $2012 / 2013-$ III/10 & 22 & 10 \\
\hline $2014 / 2015-$ III/11 & 9 & 6 \\
\hline skupaj & 160 & 64 \\
\hline
\end{tabular}

Primeri pomensko ustreznih ali sprejemljivih prevodov:

ustrezne in sprejemljive: vizitko; posetnico; sporočilo; kartico

Zraven lahko priložimo tudi vašo vizitko (III11-3)

Dodamo lahko tudi vašo kartico (III/9-6)

Paketu lahko priložimo tudi vaše sporočilo (III3-18)

Primeri neustreznih prevodov:

Pošiljki lahko priložimo vašo čestitko (III/3-1)

Paketu po želji dodamo še vaše voščilo. (III/4-1)

Dodamo lahko tudi vaše posvetilo (III/9-10)

Darilu lahko priložimo tudi vašo razglednico. (III/3-5)

Dopisnico lahko priložimo k paketu. (III/8-3)

Tja lahko priložimo tudi vašo karto. (III/11-1)

Po želji lahko priložimo tudi vašo darilno kartico. (III/4-5)

Priložimo lahko tudi vinsko karto (III/7-23)

Analiza prevodov pokaže, da je $60 \%$ vseh študentov izraz »carte« prevedla neustrezno glede na kontekst dokumenta. Neustrezni prevodi so nazoren primer pripisovanja pomena na podlagi lastnih izkušenj, torej pomena, ki je prevajalcu najbližji in najbolj poznan. »Carte« je beseda, ki so poznajo vsi študenti, zato je intuitivno ne prepoznajo kot izraz, ki bi imel specifičen pomen. Pa vendar ima beseda veliko pomenov in prevod je neizogibno odvisen od konteksta in prevajalčeve presoje o ustreznosti. »Sporočilo«, »kartica«, »vizitka« ali »posetnica« ustrezajo široki paleti situacij, v katerih podjetje ali posameznik podari vino.

Pogovor s študenti je pokazal, da je večino študentov, ki so uporabili prevodno rešitev »voščilnica« in »čestitka« zavedlo to, da gre za »darilne pakete« in so pomislili 
na darilo ob osebnem prazniku ali izjemnem dogodku (rojstni dan, novo leto, zaključek študija). Pri drugih napačnih prevodih gre bodisi za dobesedni prevod (karta) bodisi za površno ali nepremišljeno pripisovanje pomena (dopisnica, darilna kartica, vinska karta). Res je sicer, da noben od neustreznih prevodov ne predstavlja hude vsebinske napake, ki bi lahko imela resne finančne posledice, gre pa za pogosto napako pri mladih in neizkušenih prevajalcih in predvsem v vseh situacijah, kje prevajalec ne more zanesljivo razbrati pomena in konteksta.

Didaktično je to izredno zanimiv primer, saj pomaga študentom ozavestiti nevarnost, ki jo predstavljajo ustaljeni pomeni besed in izrazov ter površno posploševanje in prisojanje enega samega pomena brez natančnega in pozornega razumevanja pomena in sporočila.

Analiza napak v prevodih besedila »Conditions générales de vente« je pri vseh generacijah študentov pokazala na težave pri prevajanju izrazov, stavčnih struktur in povedi, ki so značilne za komercialna besedila in pravno-komercialni slog.

Težave in napake se pojavljajo na treh ravneh:

1. strokovni izrazi in specifični komercialni frazemi - »Les prix s'entendent départ cave«, »droits, TVA, verre«, »frais de port«, »bons de transport«, »assorties selon commande «, »livreur «.

Analiza napak je pokazala, da večina študentov ni raziskala pomena in poiskala ustreznic v slovenskih strokovnih virih. Med napakami so vsi najpogostejši vzroki, od interference in dobesednega prevajanja (»Cene pomenijo odhod iz kleti«), napak iz strahu pred interferenco (»Kuponi za popust«), neustrezne uporabe slovarja (»pravice«, »kozarec«) in neustrezne uporabe splošnega znanja in lastnih izkušenj. Te napake pa so vsekakor povezane tudi z nepoznavanjem zunajjezikovne strokovne stvarnosti.

2. povedi s pravno-komercialno skladnjo - »Agréées au départ de nos caves, les marchandises voyagent sous la responsabilité des transporteurs et destinataires.« »Dans l'intérêt de nos clients, nous leur conseillons de vérifier nos colis en présence du livreur et de faire immédiatement les réserves qui s'imposent en cas d'avarie ou de litige.«

Težave pri prevodih teh dveh povedi imajo številne vzroke, od nezadostnega znana francoskega jezika, nenatančnega branja izhodiščnega besedila, do površnosti pri preformuliranju ter nenatančnost pri pregledovanju končne verzije in nezadostno preverjanje sprejemljivosti (smiselnosti) izreka v slovenščini.

3. «nekomercialni« izrazi, ki jih študenti pomensko niso ustrezno umestili v komercialni kontekst - »carte«. Napake v prevodih kažejo na eni strani na premajhno 
pozornost pri branju (in površno razumevanje), predvsem pa na napačno prisojanje enega pomena, bodisi najpogostejšega ali prevajalcu najbolj znanega, brez razmisleka o umeščenosti v sobesedilo in kontekst.

Prevajanje tega besedila pomeni za študente prvi stik z besedilom pravno-komercialne narave, zato so bile napake in težave pričakovane, analiza teh napak in povratna informacija za študente pa je v prvi vrsti namenjena ozaveščanje o vrstah napakah in posledicah teh napak. Če povzamemo misel Christiane Nord: »Translation is learned by translating.« (1991: 146), nam ta raziskava potrdi, kako pomembno je, da študenti na lastnih napakah odkrivajo zakonitosti besedil in njihove sporočilnosti. Študenti so bili opozorjeni, da gre za specifično strokovno besedilo in čeprav so ga racionalno prepoznali in analizirali kot strokovno besedilo, prepoznali zahtevnost komercialnih formulacij in formalnega sloga ter vedeli, da prevajanje takega besedila zahteva raziskovanje in preučevanje strokovnih virov, ostaja njihov odnos pri prevajanju na splošni in literarni ravni, odkrito nezaupljivi so do komercialnih formulacij in besedišča (»franko klet«) in kritični do stila, ki ga ne poznajo (na vajah veliko študentov označi pravno-komercialni stil za »slab« in »nemogoč«), kar se v prevodih kaže v neformalnem stilu in načinu izražanja.

Večini študentov prevod tega besedila obenem pomaga ozavestiti njihove omejitve in osebnostne lastnosti. Omejitve v smislu nezadostnega znanja francoščine, težav pri preoblikovanju v slovenščino, pogosto tudi težav pri tvorjenju besedil v slovenščini. Na drugi strani pa tudi osebnostne lastnosti in kompetence, predvsem kar zadeva natančnost, vztrajnost, disciplino in motivacijo za spopadanje z različnimi vrstami besedil.

\section{7}

\section{ZAKLJUČEK}

Prevajanje avtentičnih besedil z različnih strokovnih področij je za študente izrednega pomena in jim pomaga ozavestiti naravo prevajalskega dela, pri katerem ne gre le za to, da besedilo razumejo in znajo povzeti njegovo sporočilo, ampak morajo besedilo tudi natančno, jezikovno in strokovno ustrezno prenesti v drug jezik. Prevajanje strokovnih besedil pomeni odmik od splošnega in literarnega jezika, kar je za mlade prevajalce praviloma vstop na področje, na katerem nimajo osebnih izkušenj in kjer morajo zaupati virom in prevodnim rešitvam, ki so jim tuje in nepoznane. Didaktična funkcija prevajanja strokovnih besedil zato temelji na premišljeni izbiri avtentičnih besedil in sistematičnem pregledovanju in komentiranju napak v prevodih študentov. Na podlagi lastnih napak lahko študent ozavesti težavnost prenosa iz enega jezika $\mathrm{v}$ drugega, predvsem pa izkustveno spozna, da pri prevajanju poslovnih besedil ne gre le za vprašanje razumevanja, ampak predvsem potrpežljivega in natančnega iskanja pravih virov, razumevanja odnosov in konteksta ter natančnost pri izražanju v ciljnem jeziku. 


\section{BIBLIOGRAFIJA}

BASTIN, Georges L. (2003) Aventures et mésaventures de la créativité chez les débutants. Meta : journal des traducteurs/Meta: Translators' Journal 48 (3), 347-360.

BEEBY, Allison (2000) Evaluating the development of translation competence. C. Schäffner in B. Adab (ur.), Developing Translation Competence. Amsterdam/Philadelphia: John Benjamins, 185-197.

DANCETTE, Jeanne (1997) Mapping Meaning and Comprehension in Translation. J. H. Danks (ur.), Cognitive Processes in Translation and Interpreting. Thousand Oaks: Sage Publications, 195-209.

DÉJEAN LE FÉAL, Karla (1993) Pédagogie raisonnée de la traduction. Meta : journal des traducteurs/Meta: Translators' Journal 38 (2), 155-196.

DOBNIK, Nadja (2011) Analiza napak v prevodih študentov v funkciji načrtovanja in razvijanja predmetov francoskega jezika $v$ okviru študijskega programa prevajalstva. Doktorska disertacija. Ljubljana: Filozofska fakulteta.

EYCKMANS, June/Philippe ANCKAERT (2017) Item-Based Assessment of Translation Competence: Chimera of Objectivity versus Prospect of Reliable Measurement. Linguistica Antverpiensia 16, 40-56.

GILE, Daniel (2005) La traduction. La comprendre, l'apprendre. Paris: PUF.

Francosko-slovenski slovar. Ljubljana: Državna založba Slovenije, 1984.

KIRALY, Donald (2000) A Social Constructivist Approach to Translator Education: Empowermaent from Theory to Practice. Manchester: St. Jerome Publishing.

KOCKAERT, Hendrik J./Winebert SEGERS (2014) Evaluation De La Traduction: La Méthode PIE. Turjuman 23, 232-250.

KUSSMAUL, Paul (1995) Training the translator. Amsterdam: John Benjamins Publishing Company.

NORD, Christiane (1991) Text analysis in translation. Theory, Methodology, and Didactic Application of a Model for Translation-Oriented Text Analysis. Amsterdam, Atlanta: Rodopi.

NORD, Christiane (1992) Text Analysis in Translator Training. C. Dollerup (ur.), Teaching translation and interpreting: training, talent and experience. Amsterdam, Philadelphia: John Benjamins Publishing, 39-48.

POKORN KOCIJANČIČ, Nike/Jason BLAKE/Donald REINDL/Agnes PISANSKI PETERLIN (2019) The influence of directionality on the quality of translation output in educational settings. The Interpreter and Translator Trainer, https://doi.org/10.1 080/1750399X.2019.1594563.

PYM, Anthony (1992) Translation error analysis and the interface with language teaching. C. Dollerup (ur.), Teaching translation and interpreting: training, talent and experience. Amsterdam, Philadelphia: John Benjamins Publishing, 279-288. 


\section{PRILOGA:}

\section{CONDITIONS GENERALES DE VENTE}

Nos prix s'entendent départ cave. Droits, TVA, verre et emballage compris.

- Frais de port à votre charge.

- Expéditions en cartons de 12 bouteilles assorties selon commande.

- $\quad$ Nous acceptons les bons de transport SNCF à tarif réduit.

- Contactez vos amis pour réaliser un envoi groupé et bénéficier de conditions avantageuses.

Remise $2 \%$ à partir de 60 bout. $-3 \%$ à partir de 120 bout. - $4 \%$ à partir de 240 bout. $-6 \%$ à partir de 360 bout. - 10\% à partir de 480 bout. (Pour commande plus importante, veuillez nous consulter).

PORT GRATUIT à partir de 600 bouteilles.

- Les expéditions à partir de 200 bouteilles se font en palette, les frais de port étant nettement moins onéreux. Les bouteilles logées dans cette dernière sont mises dans des cartons de 12 bouteilles avec marquage sur chaque carton de son contenu.

- COLIS-CADEAUX : Nous expédions les cartons de votre choix directement à l'adresse que vous nous indiquez. Nous pouvons y joindre votre carte.

IMPORTANT : Agréées au départ de nos caves, les marchandises voyagent sous la responsabilité des transporteurs et destinataires.

Dans l'intérêt de nos clients, nous leur conseillons de vérifier nos colis en présence du livreur et de faire immédiatement les réserves qui s'imposent en cas d'avarie ou de litige.

PAIEMENT : par chèque bancaire ou virement postal CCP Strasbourg $30405 \mathrm{~J}$ dès réception de la facture. 


\section{POVZETEK}

Prevajanje avtentičnih besedil s področja ekonomije in komercialnega poslovanja je pomemben del izobraževanja bodočih strokovnih prevajalcev. Prevajanje strokovnih besedil pomeni za večino študentov prevajalstva prvi odmik od splošnega in literarnega jezika in vstop na področje, na katerem nimajo osebnih izkušenj in kjer morajo zaupati virom in prevodnim rešitvam, ki so jim tuje in nepoznane. Didaktična funkcija prevajanja strokovnih besedil temelji na premišljeni izbiri avtentičnih besedil in sistematičnem pregledovanju in komentiranju napak v prevodih študentov. $\mathrm{Na}$ podlagi povratne informacije o napakah lahko študent ozavesti težavnost prenosa iz enega jezika v drugega, predvsem pa izkustveno spozna, da pri prevajanju poslovnih besedil ne gre le za vprašanje razumevanja, ampak predvsem potrpežljivega in natančnega iskanja pravih virov, razumevanja odnosov in konteksta ter natančnost pri izražanju v ciljnem jeziku. Članek predstavlja rezultate empirične raziskave, narejene na prevodih komercialnega besedila - Conditions de vente, ki so ga prevajali študenti enajstih generacij med letoma 1999/2000 in 2014/2015. Rezultati razkrivajo težave in napake na več ravneh, tako pri prevajanju komercialnih izrazov in frazemov, pri razumevanju in prevajanju skladenjskih struktur, kot tudi težave, značilne za študente in mlade prevajalce, od pomanjkanja splošne izobrazbe in neustreznega tvorjenja besedil v slovenščini do pomanjkanja vztrajnosti, natančnosti in motivacije za ustrezno izpeljavo prevoda.

Ključne besede: analiza napak, didaktika prevajanja, jezik stroke, prevajanje komercialnih besedil, strokovno prevajanje

\section{ABSTRACT}

\section{The challenges of technical translation faced by young translators - examples of errors in the translations of a commercial text}

The translation of authentic texts from economics and commerce is an important part of educating future professional translators. For most students, technical translation represents the first deviation from the general and literary languages, venturing into an area where they cannot resort to personal experience and have to trust resources and solutions they find foreign. The didactic function of specialized translation is rooted in the careful selection of authentic texts and a systematic review of student translations with error feedback. This allows students to grow conscious of the challenges of specialized translation as they experience first-hand that they need to not only comprehend the text, but also patiently and carefully look for the right resources, understand relations and contexts, and use precise target expressions. The article presents the results of an empirical study of student translations of the text "Conditions de vente" completed between 1999/2000 and 2014/2015. The results show issues and errors on multiple levels, for example with commercial expressions and idioms or the comprehension and translation of syntactic structures, as well as issues typical of 
students and young translators, such as insufficient general knowledge, inadequate text formation in Slovene, and insufficient persistence, precision and motivation to produce a suitable translation.

Keywords: error analysis, didactics of translation, languages for specific purposes, translation of commercial texts, technical translation

\section{RÉSUMÉ}

\section{Quelques difficultés des jeunes traducteurs dans les traductions de textes professionnels - analyse d'erreurs dans les traductions de texte commercial}

La traduction de textes authentiques relevant du domaine de l'économie et du commerce est un élément essentiel dans la formation des futurs traducteurs professionnels. Pour la plupart des étudiants suivant cette formation, la traduction de textes professionnels représente un premier décalage avec la langue générale et littéraire, et en même temps, une entrée dans un domaine où ils n'ont aucune expérience personnelle et où ils doivent faire confiance à des sources et à des solutions de traduction qui leur sont étrangères et inconnues. La fonction didactique de la traduction de textes professionnels repose sur une sélection réfléchie de textes authentiques ainsi que sur les commentaires des erreurs produites par les étudiants. L'article présente les résultats d'une étude empirique basée sur les traductions d'un texte commercial portant sur les conditions de vente, traduit par onze générations d'étudiants entre 1999-2000 et 2014-2015. Les résultats révèlent des difficultés à plusieurs niveaux, à la fois dans la traduction de termes commerciaux, dans la compréhension et la traduction de structures syntaxiques, ainsi que des problèmes spécifiques aux jeunes traducteurs, du manque de culture générale et de rédaction en slovène au manque de persévérance, de précision et de motivation pour mener à bien leurs traductions.

Mots-clés: analyse d'erreurs, didactique de la traduction, langue de spécialité, traduction de textes commerciaux, traduction professionnelle 